\title{
PENERAPAN E-COMMERCE MENGGUNAKAN METODE BUSINESS MODEL CANVAS PADA TOKO COMMA SNEAKERS
}

\author{
Randy Dandi ${ }^{1}$, Samsinar ${ }^{2)}$ \\ ${ }^{1}$ Sistem Informasi, Fakultas Teknologi Informasi, Universitas Budi Luhur \\ ${ }^{1,2} \mathrm{Jl}$. Raya Ciledug, Petukangan Utara, Kebayoran Lama, Jakarta Selatan 12260 \\ E-mail : randydandi1996@gmail.com ${ }^{1)}$, samsinar@budiluhur.ac.id ${ }^{2)}$
}

\begin{abstract}
Abstrak
Electronic Commerceatau biasa disebut E-Commercemerupakan kegiatan jual beli yang dilakukansecara elektronik menggunkan jaringan internet. Sesuai latar belakang yang telah disajikan, penelitian ini akan membuat sistem e-commerceyang bertujuan menampilkan seluruh jenis produk yang ditawarkan untuk dipromosikan sesuai harga yang ditetapkan. Sehingga seller dan buyerbisa mengakses produk dan dapat bertransaksi secara online kapan saja. Maka sebab itu, dirancang dan dibangun sistem e-commerce di toko Comma Sneakers yang sanggup memberikan informasi mengenai produk dan dapat melakukan pemesanan produk secara online, sehingga konsumen dapat mengakses dan memesan produk di toko Comma Sneakers. Dalam merancang basis data, metodelogi yang digunakan adalah model data Class Diagram. Oleh karena itu penerapan e-commerce untuk membuat transaksi ini sangat baik dan menguntungkan untuk siapapun yang menggunakannya.
\end{abstract}

Kata kunci: E-Commerce, Sneakers, Produk.

\section{PENDAHULUAN}

1.1. Latar Belakang

ElectronicCommerce (E-Commerce) adalah perdagangan elektronikyang meliputi kegiatan pembelian dan penjualan, pemasaran produk, jasa dan informasi [1]. Konsep toko online atau $e$ commerce dapat memangkas banyak biaya operasional karena penjual tidak diharuskan punya toko fisik.

Sneakers menjadi tren lifestyle baru yang menjamur di kalangan masyarakat Indonesia. Tidak heran bahwa snekaers menjadi atribut penting pada diri individu dalam menentukan gaya berbusana. Umumnya usaha dengan konsep Sneakers mengutamakan kebutuhan untuk remaja kekinian dan mahasiswa. Lewat hasil wawancara yang dilakukan pada Comma Sneakers, penjualan toko saat ini sedikit menurun. Seiring berkembangnya Comma Sneakers,sistem yang dikelolasekarang belum adanyateknologi komputer, tidak ada media elektronik untuk jual belijarak jauh yang diharapkan bisa mempermudah transaksi untuk mempromsikan produk produk sneakers.

Tujuan dari penulisan penelitian ini untukMembuat model e-commercedengan harapan menjadikan rancangan e-commerce iniuntuk membantumenyelesaikan permasalahan jual beli yang sebelumnya dilakukan secara manual menjadi efisien dan berbasis online melalui rancanganecommerce, Rancangan E-Commerce pada Comma Sneakers adalah sebagai pengembangan sistem penjualan pada Comma Sneakers yang mempunyai janggalan dalam kurangnya peningkatan pendapatan yang dialami Comma Sneakers, dan dirancang untuk meningkatkanpendapatan, menyediakan fasilitas untuk pendataan transaksi pesanan dan pengelolaan data stok agar tidak menumpuk dan pengevaluasian penjualan melalui laporan yang lebih informative, menambahkan jumlah pelanggan yang ada karena dengan E-Commerce penjualan dapat dilakukan dimana saja dan kapansaja.

Untuk memudahkanpenelitan ini, dibuatlah susunan kerangka kerja yang jelas tahapannya. Tahapan ini merupakan salah satu langkah awal yang harus dilakukan dalam penyelesaian masalah yang akan dibahas. Inilahgambar kerangka kerja penelitian yang digunakan penulis:

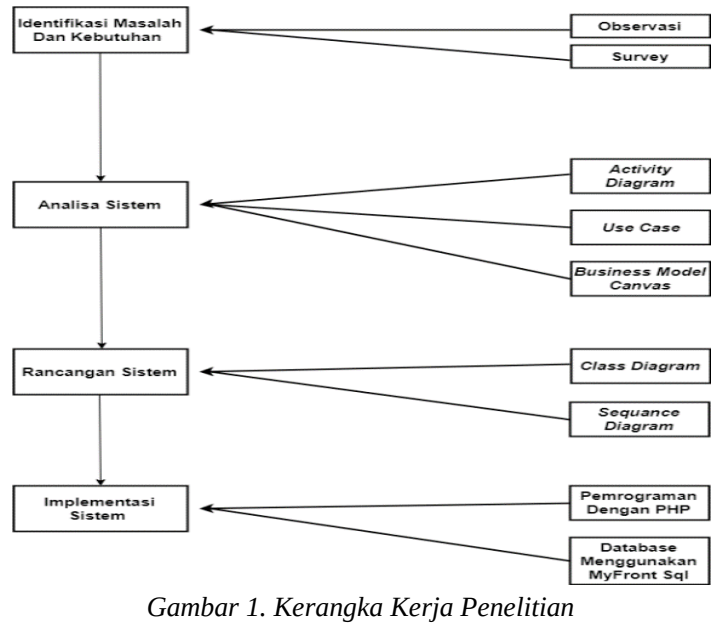

Adapun konsep dasar E-Commerce yaitu:

1. Automation manual

Otomasi bisnis proses sebagai proses 
2. Streamlining/Integration efektif

Proses untuk mencapai hasil yang

3. Publishing

Kemudahan berkomunikasi dan berpromosi untuk produk atau jasa yang akan di perdagangkan,

4. Interaction bisnis

Pertukaran informasi antar pelaku

5. Transaction

Kesepakatan dua pihak untuk berinteraksi dengan melibatkan intitusi lain sebagai fungsi pembayaran.

\subsection{Masalah}

Adapun permasalahan yang dihadapi dalam proses jual beli produk Comma Sneakers sebagai berikut:

a. Stok lama yang dimiliki Comma Sneakers terlihat usang, mengakibatkan pihak toko mengalami kesulitan dalam memasarkan produk

b. Area penjualan hanya disekitar lokasi menyebabkan penghasilan tidak meningkat

c. Proses bisnis masih menggunakan manual sehingga informasi yang dihasilkan lambat dan kurang akurat

d. Pemilik sulit mencari informasi produk dikarenakan proses bisnis penjualan tidak terkomputerisasi, akibatnya staf penjualan tidak mengetahui informasi produk sehingga informasi yang dihasilkan lambat dan kurang akurat

\section{METODE PENELITIAN}

\subsection{Pengumpulan Data}

Berikut adalah cara pengumpulan data beserta penjelasannya yang penulis gunakan dalam hal penelitian tugas akhir:

a. Observasi

Pada tahapan ini, kegiatan yang dilakukan yaitu mengamati, melihat dan menganalisa proses untuk mendapatkan data yang dibutuhkan pada Comma Sneakers, mulai dari proses pemesanan, produk yang dimiliki Comma Sneakers, staf toko dalam menuangkan informasi produk kepada pembeli atau konsumenserta promosi barang barang apa saja yang dimiliki.

b. Wawancara

Penulis memberi pertanyaan dan berkomunikasi dengan pemilik sneakers, bagaimana tahapan proses penjualan pada Comma Sneakers, mulai dari proses pemesanan, pengiriman dan data produk.
Maka dapat disimpulkan bahwa wawancara adalah merupakan kegiatan tanya jawab yang terjadi secara langsung antara dua orang atau lebih. Pewawancara biasa disebut dengan interviewer sementara orang yang akan diwawancarai dinamakan interviewer.

c. Arsip

Catatan rekaman kegiatan atau sumber informasi untuk merancang sebuah e-commerce pada Comma Sneakers, Data primer dari arsip ini penulis gunakan untuk kajian teoritis mengenai penelitian yang penulis susun.

d. Kepustakaan

Adapun 3 (tiga) narasumber peneliti yang diangakat dalam menyusun penelitian ini diantaranya:

Penelitian oleh [3], yaitu Optimasi Ecommerce dengan Penerapan Teknik SEO (Search Engine Optimization) untuk meningkatkan penjualan pada UKM Nida Sarirangan, Jurnal Impact: Implementation and Action, Vol. 1 No. 1, 2018, Tujuan dari penelitian ini yaitu untuk mempermudah dalam pencarian website lebih mudah pada toko Nida Sasirangang.

Penelitian selanjutnya[4], yaitu "Membangun Aplikasi E-Commerce Dengan System Penunjang Keputusan Di Toko Islam Malang”. Jurnal J-INTECH Vol. 6 No. 1 Juni 2018 ISSN: 2303-1425 dan E-ISSN: 2580720X, Tujuan penelitian ini memberikan rekomendasi produk pada pengunjung yang akan membeli barang di toko online ini.

Penelitian oleh [5] yaitu "Penerapan ECommerce Pada Gudang Distro Palembang”. Tujuan dari penelitian ini yaitu ingin memudahkan proses pembelian. Jurnal Vol 5, No 1 (2016). Hasil dan Kesimpulan Penggunaan sistem ini mudah digunakan oleh pelanggan.

\subsection{Teknik Analisa Data}

Berikut tahapan-tahapan Analisa sistem:

1. Use Case Diagram

Use case diagram adalah sesuatu atau proses merepresentasikan hal-hal yang dilakukan olehaktor dalam menyelesaikan sebuah pekerjaan[6]. Biasanya proses inidigunakan untuk menggambarkan interaksi antara pengguna sistem dengan kasus yang disesuaikan dengan langkah-langkah yang telah ditentukan.

2. Activity Diagram

Teknik inidigunakan untuk memodelkan aktivitaskinerja proses bisnis yang dilengkapi urutan aktivitas didalam suatu proses[7]. 


\section{HASIL DAN PEMBAHASAN}

\subsection{Business Model Canvas}

Business Model Canvas (BMC)merupakan suatu kerangka kerja atau framework yangmenjelaskan bagimana cara model Bisnis ini yang disajikan dalam bentuk kominikasi secara penglihatan (visual) berupa kanvas lukisan, agar dapat dipahami dengan jelas. BMC digunakan untuk menjelaskan secara singkat, memvisualisasikan, menilai, dan mengubah suatu model bisnis, supaya dapat menghasilkan kinerja yang memuaskan [2]. Seperti yang terlihat pada Gambar 2:

\begin{tabular}{|c|c|c|c|c|c|}
\hline \multirow[t]{2}{*}{$\begin{array}{l}\text { Key } \\
\text { Partners } \\
\text { - Supplie } \\
\text { r sepatu } \\
\text { - JNE } \\
\text { - Bank }\end{array}$} & \begin{tabular}{|l} 
Key Activates \\
- Proses \\
pengadaan \\
barang \\
- $\begin{array}{l}\text { Pengirima } \\
\text { n barang }\end{array}$
\end{tabular} & \multirow{2}{*}{\multicolumn{2}{|c|}{\begin{tabular}{|l|} 
Value \\
Proposition \\
- Menjual \\
sepatu \\
berkualita \\
s original \\
yang \\
sudah \\
terjamin \\
mutunya
\end{tabular}}} & $\begin{array}{l}\text { Customer } \\
\text { Relationship } \\
\text { - Promo } \\
\text { - Diskon }\end{array}$ & \multirow{2}{*}{\begin{tabular}{|l} 
Customer \\
Segments \\
- Mahasiswa \\
i \\
- Anak \\
sekolah \\
\\
\\
\end{tabular}} \\
\hline & $\begin{array}{l}\text { Key Resources } \\
\text { - Bahan baku } \\
\text { berkualitas } \\
\text { import }\end{array}$ & & & \begin{tabular}{|l} 
Channels \\
\\
- Instagram \\
- E- \\
Commerc \\
e
\end{tabular} & \\
\hline \multicolumn{3}{|c|}{$\begin{array}{l}\text { Cost Structure } \\
\text { Biaya: } \\
\text { Produk, gaji pegawai, transport }\end{array}$} & \multicolumn{3}{|c|}{$\begin{array}{l}\text { Revenue Streams } \\
\text { - Profit: } \\
\text { Penjualan produk dari hasil toko dar } \\
\text { online }\end{array}$} \\
\hline
\end{tabular}

Gambar 2. Business Model Canvas

Terdapat 9 elemen dalam business model canvass pada Toko Comma Sneakers.

a. Key Partners

Key Partners Comma Sneakers adalah connection dengan pihak luar hanya dengan penyedia jasa pengiriman barang yaitu PT Tiki Jalur Nugraha Ekakurir (JNE), supplier dan Bank

b. Key Activity

Key Activities Comma Sneakers memberikan pelayanan yang ramah untuk memuaskan pelanggannya.

c. Value Proposition

Value Proposition mempermudahan untuk mencari produk terbaru terhadap pelanggan.

d. Customer Relationship

Customer relationship Comma Sneakers memberikan promo menarik, memberikan diskon seperti akhir tahunan.

e. Customer Segments

Customer Segments pada Comma Sneakers mengarah ke Mahasiswa/Mahasiswi dan anak Sekolah.

f. Key Resources

Key Resources pada Comma Sneakers ialah dengan menggunakan bahan baku berkualitas import.

g. Channel
Channel Comma Sneakers Menggunakan sosial media dan internet untuk mempopulerkan Comma Sneakers seperti Instagram.

\section{h. Cost Structure}

Cost Structure pada Comma Sneakers yaitu meliputi biaya produksi, gaji pegawai, transport, Internet.

i. Revenue Stream

RevenueStream dari Comma Sneakers yaitu asset sale dimana sumber sumber pendapatan usaha diperoleh darihasil aktivitas penjualan di toko dan penjualan online pada Comma Sneakers.

\subsection{Proses Bisnis}

Sistem penjualan yang masih berjalan pada Comma Sneakers, penulis mengusulkan menggunakan sistem e-commerce untuk dapat dipakaiberbasis online dan real time tanpa batasan waktu dan tempat. Berikut ini adalah proses bisnis sistem usulan rancangan bangun sistem.

a. Penjualan Produk

Pada gambar 3 menjelesakan tentang Pelanggan dapatmemilih produk yang dipilihnya dan secara otomatismasuk ke keranjang belanja beserta jumlah produk yang dipesannya. Setelah Pelanggan selesai memilih produk, Pelanggan diminta login. Jika pelanggan sudah terdaftar, Pelanggan diminta input untuk alamat pengiriman sebagai jasa ekspedisi pengiriman barang. Jika Pelanggan belum terdaftar maka pelanggan harus daftar terlebih dahulu. saat pemesanan produk berhasil, Pelanggan mendapatkandetail pesanan dari sistem yang berisikan bukti produk yang di pesan dan jumlah yang harus dibayarkan. Lalu sistem menyimpan data pesanan yang sudah tersimpan.

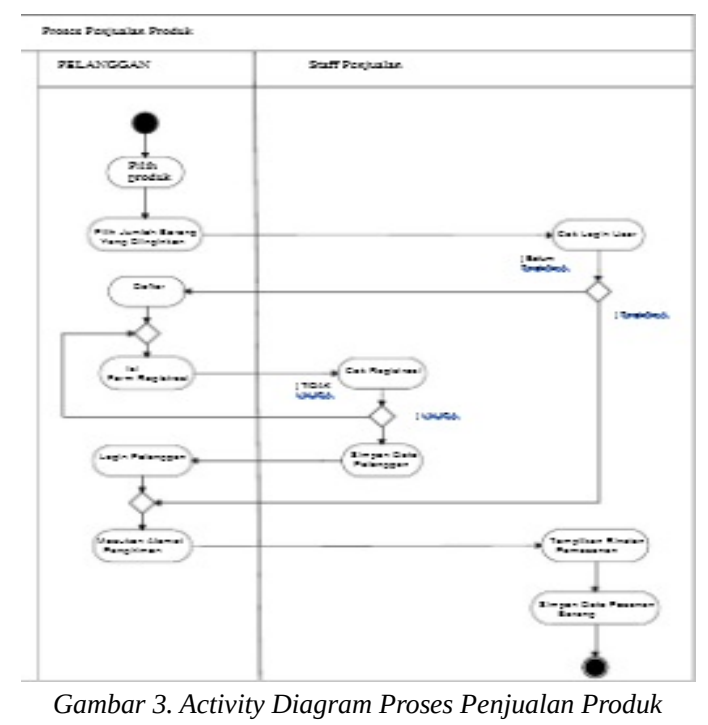


b. Pembayaran

Pada gambar 4 menjelaskan bahwa bukti Pesanan yang sudah tersimpan dan ditampilkan oleh sistem, Pelanggan disarankann harus membayar sejumlah uang sesuai dengan harga yang sudah ditentukan. Setelah itu, Pelanggan harus melakukan konfirmasi pembayaran dengan cara memasukkan Bukti Pembayaran. Lalu staf penjualan melakukan Konfirmasi pembayaran. Setelah Pelanggan melakukan konfirmasi, lalu staf penjualan mengirim nomor resi barang yang mau dikirim kepada Pelanggan.

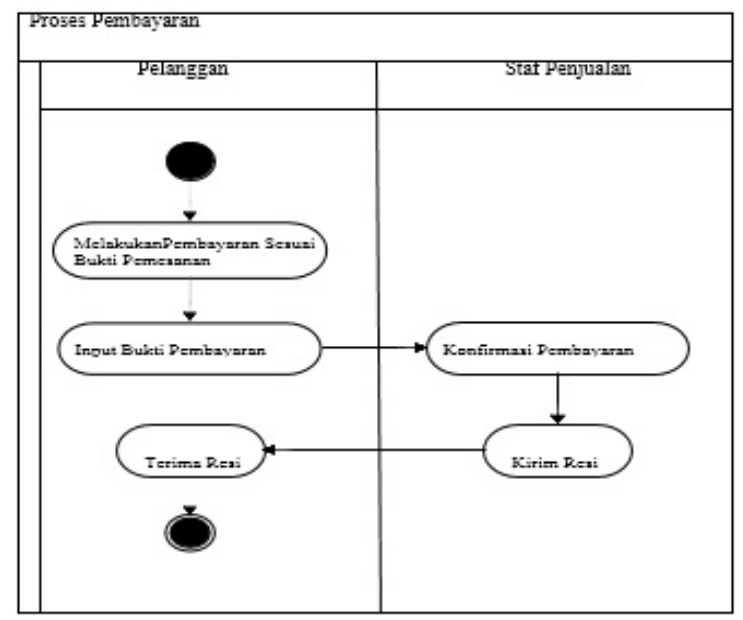

Gambar 4. Activity Diagram Proses Pembayaran

c. Laporan

Pada gambar 5 menjelaskan bahwa Staf Penjualan dapat mencetak laporan penjualan. Laporan ini berisikan laporan stok produk, laporan pemesanan, laporan pembeli terbanyak, laporan penjualan, laporan produk terlaris, laporan pembayaran, dan laporan rekapitulasi penjualan untuk diberikan kepada owneertoko. Laporan stok produk berisikan laporan stok stok awal, stok terjual, stok sisa. Laporan pemesanan berisi pemesanan produk yang dilakukan pelanggan. Laporan pembeli terbanyak berisikannama pembeli yang melakukan transaksi paling banyak. Laporan status penjualan berisikan laporan status pembayaran yang dilakukan oleh pembeli. Laporan produk terlaris berisikan data produk berdasarkan nama kategori dan produk yang paling sering dibeli. Laporan pembayaran berisi data pelanggan yang telah melakukan pembayaran. Laporan rekapituasi penjualan berisi produk per kategori yang telah terjual.

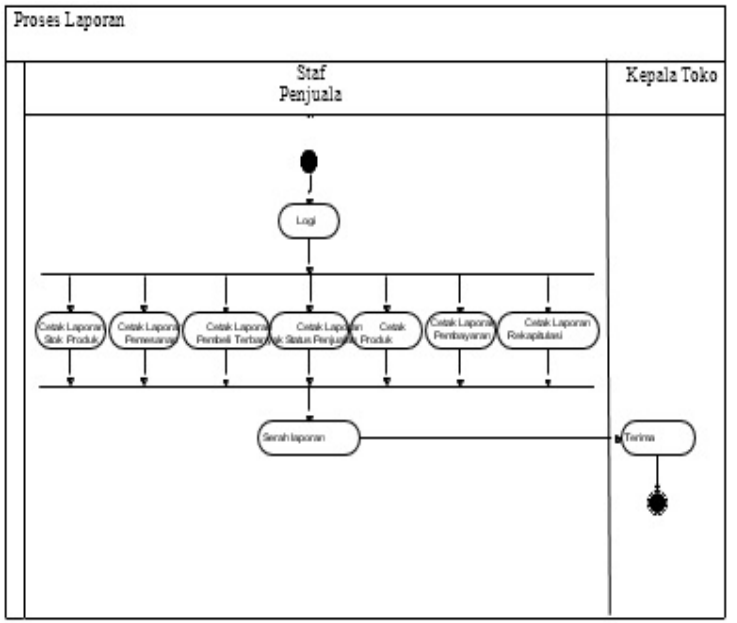

Gambar 5. Activity Diagram Sistem Usulan Laporan

\subsection{Model Sistem}

Pada Use Case Diagram Master untuk staf penjualan terdapat 3 menu master yaitu Produk, Kategori, Ongkir. Berikut Use Case Diagram Master untuk stafpenjualan yang tertera pada gambar 6 dibawah.

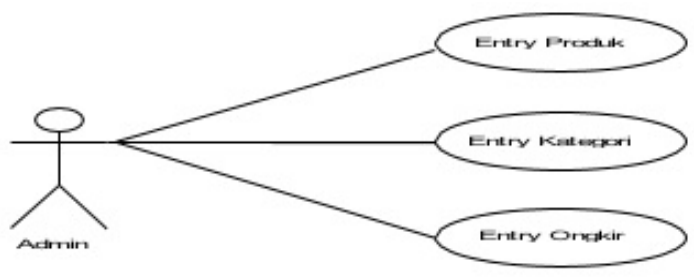

Gambar 6. Use Case Diagram Master Staf Penjualan

Pada Use Case Diagram Master untuk Pelanggan terdapat menu Entry data pribadi (Calon Pelanggan), View Kategori, View Riwayat Belanja Produk dan View Detail Penjualan. Berikut Use Case nya pada Gambar 7 dibawah ini.

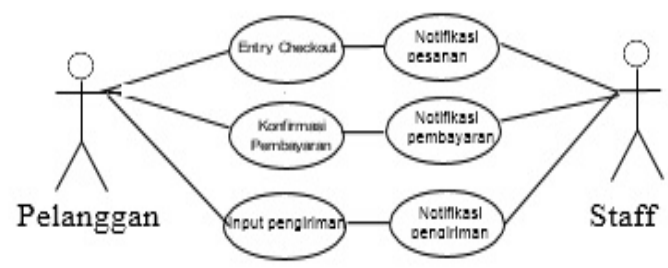

Gambar 7. Use Case Diagram Master Pelanggan

Use Case Diagram Pelanggan memiliki 2 menu transaksi yaitu Pembelian dan Konfirmasi Pembayran. Berikut adalah Use Case Diagram Transaksi untuk Pelanggan pada gambar 8 dibawah ini. 


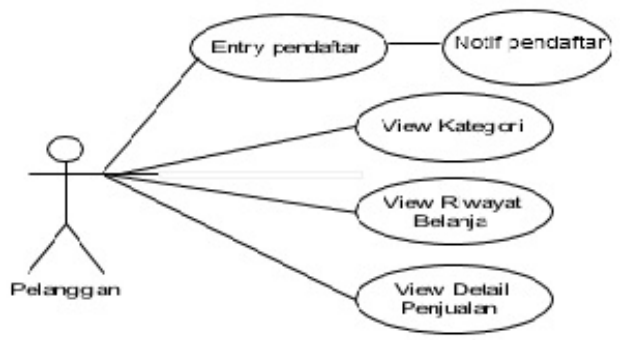

Gambar 8. Use Case Diagram Transaksi Pelanggan

Pada Use Case Diagram Laporan terdapat 7 menu Laporan yaitu Cetak Laporan Stock Barang, Cetak Laporan Pemesanan, Cetak Laporan Pembeli Terbanyak, Cetak Laporan Penjualan, Cetak Laporan Produk Terlaris, Cetak Laporan Pembayaran, Cetak Laporan Rekapitulasi Penjualan. Berikut adalah Use Case Diagram Laporan. Berikut adalah use case diagram laporan yang tertera pada gambar 9 dibawah.

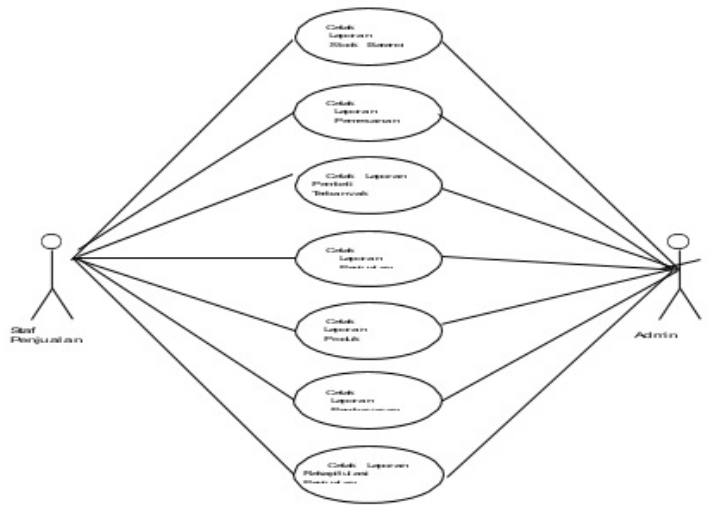

Gambar 9. Use Case Diagram Laporan

\subsection{Tampilan Layar}

a. Menu Admin

Pada Gambar 10 menggambar tentang tampilan layar admin saat login

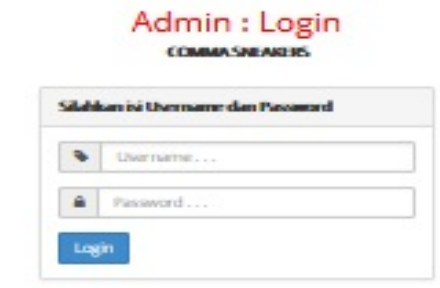

Gambar 10. Tampilan layar login Admin

b. Menu pelanggan

Pada Gambar 11 menggambar tentang tampilan layar home untuk pelanggan

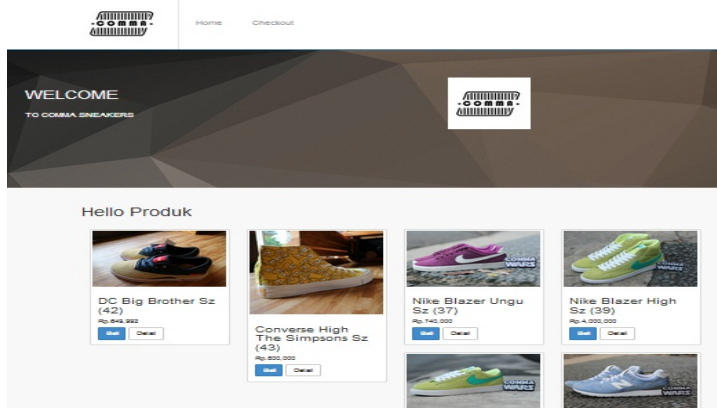

Gambar 11. Tampilan Layar Home Pelangggan

c. Transaksi Pelanggan

Pada Gambar 12 menggambarkan tampilan layar keranjang belanja setelah memilih produk yang sudah dipilih.

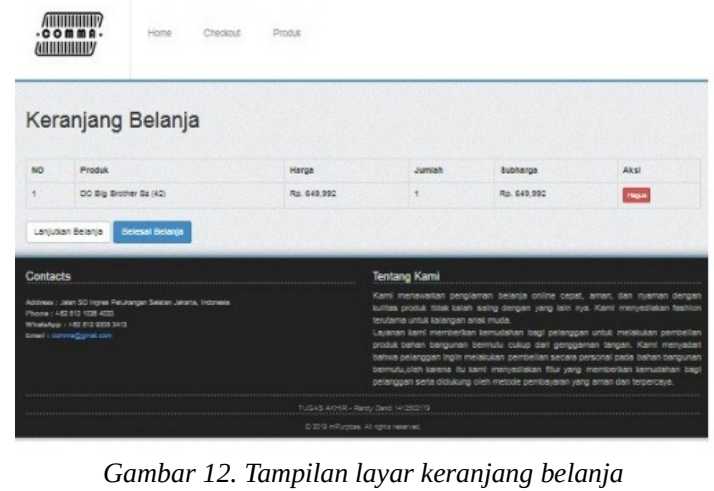

Pada Gambar 13 menggambarkan tampilan layar checkout produk yang sudah di pilih sesuai keranjang belanja

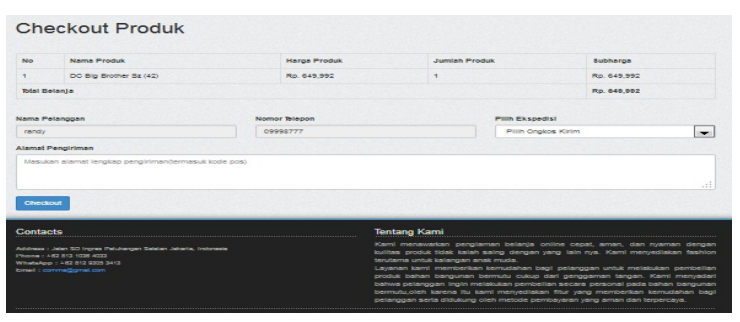

Gambar 13. Tampilan layar checkout produk

Pada gambar 14 menggambarkan tentang detail pembelian produk. Disini tercetak detail produk dan detailharga total yang harus dibayar oleh pelanggan.

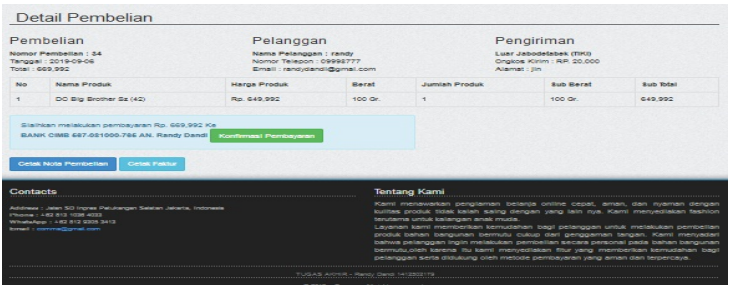

Gambar 14. Tampilan layar detail pembelian 
Pada gambar 15 menggambarkan tentang pelanggan harus mengkonfirmasi pembayaran untuk melanjutkan transaksi tersebut.

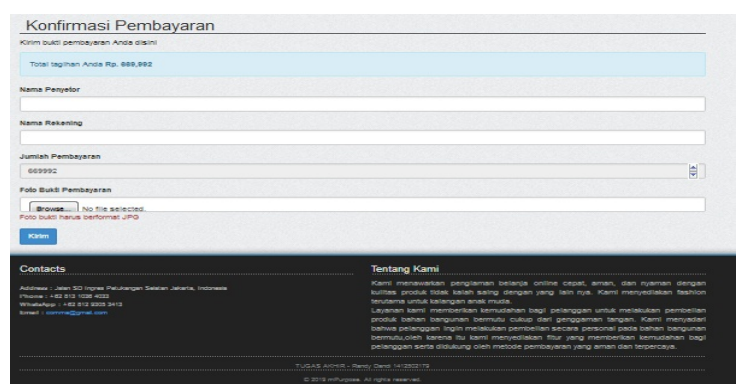

Gambar 15. Tampilan layar konfirmasi pembayaran

Jika sudah konfirmasi pembayaran, pelanggan tinggal menunggu status pembayaran di kolom riwayat belanja seperti pada gambar 16 dibawah ini.

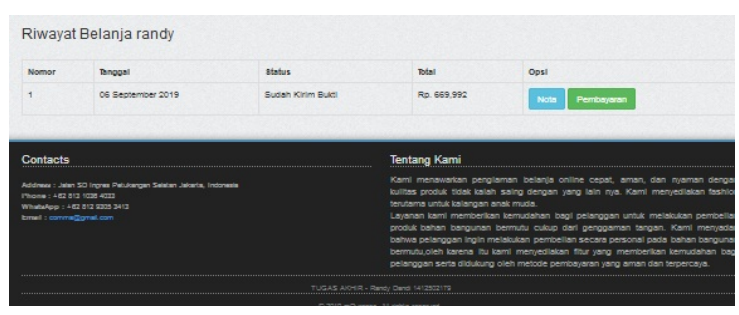

Gambar 16. Tampilan layar riwayat belanja

\section{KESIMPULAN}

Lewat hasil penelitian ini, pemenyatakan bahwa dengan merancang dan membangun $E$ Commerce di Toko Comma Sneakers, dapat simpulkan bahwa:

a. Dengan dibuatkannya fitur pencarian produk ini, pelanggan bisa melihat produk apa saja yang dijual tanpa harus datang ke toko untuk melihat produk.

b. Dengan dibuatkannya fitur pemesanan produk ini, pelanggan bisa melakukan pemesanan produk tanpa harus datang ke toko untuk melakukan pemesanan produk.

c. Dengan dibuatkannya fitur upload bukti pembayaran ini, pelanggan bisa melakukan pembayaran melalui transfer tanpa harus datang ke toko untuk melakukan pembayaran.

d. Dengan dibuatkannya fitur laporan stok produk ini, pemilik atau bagian penjualan bisa langsung melihat stok produk yang tersedia.

e. Dengan dibuatkannya fitur pengiriman produk ini, pelanggan dapat mengetahui informasi nomor resi pengiriman yang sudah dalam proses pengiriman oleh ekspedisi

\section{DAFTAR PUSTAKA}

[1] Sutrisno, S., Asyidiq, M. and Santoso, S. (2018). Perancangan Sistem Pemasangan Iklan Online Pada Aplikasi E-Commerce (E-Gemanusa) Menggunakan Metode Restful Api Dan Framework Laravel. Jurnal Ilmiah Sains dan Teknologi, Volume 2(2). pp. 119132.

[2] Pramudita, A. S. (2018). Formulasi Model Bisnis Hostel di Bandung dengan Pendekatan Value Chain dan Business Model Canvas (Studi Kasus: Pinisi Backpacker). ISEI Business and Management. Volume2(1). pp. 32-38.

[3] Pratomo, A. et al. (2018). Optimasi E-Commerce Dengan Penerapan Teknik SEO (Search Engine Optimization ) Untuk Meningkatkan Penjualan Pada UKM Nida Sasirangan. Jurnal IMPACT: Impelementation and Action.Volume.1(1), pp. 3547.

[4] Nugroho, A. A. (2018). Membangun Aplikasi ECommerce Dengan Sistem Penunjang Keputusan Metode Apriori Untuk Memberikan Rekomendasi Kepada Calon Pembeli Di Toko Islam Malang.JINTECH Journal of Information and Technology, Volume.6(1), p.11.

[5] Marcallina, D. and Wahyuningsih, D. (2016). Penerapan E-commerce dengan Metode Costumer Relationship Management (CRM) Berbasis Website (Studi Kasus: Gudang Distro Palembang). Jurnal Sisfokom (Sistem Informasi dan Komputer), Volume 5(1), p. 40. doi: 10.32736/sisfokom.v5i1.26.

[6] Mamed Rofendy Manalu. 2015. Implementasi Sistem Informasi Penyewaan Mobil Pada CV. BTN Padang Bulan Dengan Metode Waterfall.Jurnal Mantik Penusa. Volume 18(2). ISSN:2088-3943.

[7] A.SRosa, dan M.Shalahuddin. (2014). Rekayasa Perangkat Lunak Struktur dan Berorientasi Objek.Bandung: Informatika. 